\title{
Dietary carotenoid intake of individuals in the EPIC-Norfolk cohort is positively associated with percentage fat-free mass
}

\author{
R.P.G. Hayhoe ${ }^{1}$, M.A.H. Lentjes ${ }^{2}$, R.N. Luben ${ }^{2}$, K-T. Khaw ${ }^{2}$ and A.A. Welch ${ }^{1}$ \\ ${ }^{1}$ Population Health and Primary Care, Norwich Medical School, University of East Anglia, Norwich, Norfolk NR4 \\ $7 T J$ and ${ }^{2}$ Public Health and Primary Care, University of Cambridge, Cambridgeshire CBI 8RN
}

Sarcopenia, a result of decline in skeletal muscle mass and function with age, has important health implications for affected individuals including increased risk of physical frailty and falls, and consequent greater need for health and social care ${ }^{(1)}$. Sarcopenia is a complex condition, but modifiable lifestyle behaviours may represent an important target for strategies to reduce its severity through physical activity or dietary intervention ${ }^{(2)}$. In terms of nutritional factors, Vitamin D and dietary protein have been the main focus of research, but there is some limited evidence of the potential benefits of antioxidant nutrients in sarcopenia prevention ${ }^{(3)}$. Carotenoids, found in abundance in fruit and vegetables, represent a candidate group of antioxidant nutrients worthy of investigation. Thus the aim of this study was to investigate potential associations of dietary carotenoid intake and bioelectrical impedance estimated fat-free mass (as a proxy for skeletal muscle mass) in a UK population cohort of older individuals.

Data for individuals in the EPIC-Norfolk cohort ${ }^{(4)}$ of 25,639 men and women were used for analysis, as approved by The Norfolk District Health Authority Ethics Committee. Dietary nutrient intakes were estimated from 7-day food diaries and fat-free mass by bioelectrical impedance analysis (BIA) using a Tanita TBF531 scale. Multivariable regression was used to investigate percentage fatfree mass $(\mathrm{FFM} \%$; fat free mass $\div$ total mass $\times 100)$ across sex-specific quintiles of total carotene, $\beta$-cryptoxanthin, combined lutein and zeaxanthin, and lycopene. Adjusted models included age, smoking status, physical activity, social class, menopausal and HRT status in women, statin use, corticosteroid use, days of food diary completed, total energy intake, ratio of energy intake to estimated energy requirement, and protein energy intake as a percentage of total. Statistical analyses were performed using STATA (v13; Stata Corp., USA).

Mean (SD) age was $62.9(9 \cdot 0)$ years for men $(n=6350)$ and $61.5(9 \cdot 0)$ for women $(n=7990)$. Mean $(\mathrm{SD})$ percentage fat-free mass $(\mathrm{FFM} \%$ ) was $76.7(5 \cdot 8) \%$ for men and $60.9(8 \cdot 3) \%$ for women. In men, mean (SD) daily dietary intakes were $2709(1525) \mu \mathrm{g}$ carotene, 407 (570) $\mu \mathrm{g} \beta$-cryptoxanthin, 1095 (867) $\mu \mathrm{g}$ lutein and zeaxanthin, and 1424 (1658) $\mu \mathrm{g}$ lycopene; in women, intakes were 2706 (1523) $\mu \mathrm{g}$ carotene, 459 (573) $\mu \mathrm{g} \beta$-cryptoxanthin, 1140 (936) $\mu \mathrm{g}$ lutein and zeaxanthin, and 1282 (1358) $\mu \mathrm{g}$ lycopene.

\begin{tabular}{|c|c|c|c|c|c|c|c|c|c|c|c|c|c|c|}
\hline \multirow[t]{3}{*}{ Adjusted FFM $\%$} & \multicolumn{7}{|l|}{ Men } & \multicolumn{7}{|c|}{ Women } \\
\hline & \multicolumn{2}{|c|}{ Quintile1 } & \multicolumn{2}{|c|}{ Quintile3 } & \multicolumn{2}{|c|}{ Quintile5 } & \multirow[b]{2}{*}{$\mathrm{P}$ trend } & \multicolumn{2}{|c|}{ Quintile1 } & \multicolumn{2}{|c|}{ Quintile3 } & \multicolumn{2}{|c|}{ Quintile5 } & \multirow[b]{2}{*}{$\mathrm{P}$ trend } \\
\hline & Mean & SD & Mean & $\mathrm{SD}$ & Mean & $\mathrm{SD}$ & & Mean & $\mathrm{SD}$ & Mean & $\mathrm{SD}$ & Mean & $\mathrm{SD}$ & \\
\hline Total carotene & $76 \cdot 3$ & $4 \cdot 5$ & $76 \cdot 7^{\mathrm{c}}$ & $4 \cdot 4$ & $77 \cdot 3^{\mathrm{a}}$ & $4 \cdot 5$ & $<0.001$ & $60 \cdot 7$ & $6 \cdot 9$ & $60 \cdot 6$ & $6 \cdot 8$ & $61 \cdot 6^{\mathrm{a}}$ & $6 \cdot 9$ & $<0.001$ \\
\hline$\beta$-cryptoxanthin & $76 \cdot 3$ & $4 \cdot 5$ & $76 \cdot 7^{\mathrm{c}}$ & $4 \cdot 4$ & $77 \cdot 0^{\mathrm{a}}$ & $4 \cdot 5$ & $0 \cdot 014$ & $60 \cdot 5$ & $6 \cdot 9$ & $60 \cdot 9$ & $6 \cdot 8$ & $61 \cdot 2^{\mathrm{b}}$ & $6 \cdot 8$ & $0 \cdot 023$ \\
\hline Lutein \& zeaxanthin & $76 \cdot 3$ & $4 \cdot 5$ & $76 \cdot 8^{b}$ & $4 \cdot 4$ & $77 \cdot 1^{\mathrm{a}}$ & $4 \cdot 5$ & $<0.001$ & $60 \cdot 4$ & $6 \cdot 9$ & $60 \cdot 9^{c}$ & $6 \cdot 7$ & $61 \cdot 9^{\mathrm{a}}$ & $6 \cdot 8$ & $<0.001$ \\
\hline Lycopene & $76 \cdot 7$ & $4 \cdot 5$ & $76 \cdot 7$ & $4 \cdot 4$ & $76 \cdot 7$ & $4 \cdot 5$ & 0.702 & $60 \cdot 7$ & $6 \cdot 7$ & $61 \cdot 0$ & $6 \cdot 9$ & $61 \cdot 2^{\mathrm{c}}$ & $6 \cdot 8$ & 0.023 \\
\hline
\end{tabular}

${ }^{\mathrm{a}} \mathrm{p}<0.001,{ }^{\mathrm{b}} \mathrm{p}<0.01,{ }^{\mathrm{c}} \mathrm{p}<0.05$ versus quintile 1 .

Significant positive trends in adjusted FFM\% were evident across dietary intake quintiles of total carotene, $\beta$-cryptoxanthin, and combined lutein and zeaxanthin, in both men and women, and lycopene in women alone. The largest difference between specific quintiles was seen for combined lutein and zeaxanthin intake in women, where adjusted FFM $\%$ was $2.5 \%$ greater $(\mathrm{p}<0.001)$ in quintile 5 than quintile 1.

This study has provided novel evidence, observing for the first time in a UK population cohort, that percentage fat-free mass is positively associated with dietary intake of specific carotenoids in both men and women. Further investigation is now required to determine the mechanisms behind this observation, and confirm whether optimising dietary carotenoid intake could be a strategy for management or prevention of sarcopenia.

1. Welch A. (2014) Proc Nut Soc 73, 16-33.

2. Denison H, Cooper C, Sayer A, Robinson S. (2015) Clin Interv Aging 10, 859-69.

3. Kelaiditi E, Jennings A, MacGregor A, et al. (2012) Proc Nut Soc 71, E191.

4. Day N, Oakes S, Luben R, et al. (1999) Br J Cancer 80, 95-103. 